https://helda.helsinki.fi

Localization and Expression of Sirtuins 1, 2, 6 and Plasticity-

Related Proteins in the Recovery Period after a

Photothrombotic Stroke in Mice

Demyanenko, Svetlana

2020-10

Demyanenko , S , Gantsgorn , E , Rodkin , S \& Sharifulina , S 2020 , ' Localization and Expression of Sirtuins 1, 2, 6 and Plasticity- Related Proteins in the Recovery Period after a Photothrombotic Stroke in Mice ' , Journal of Stroke \& Cerebrovascular Diseases , vol. 29 , no. 10,105152 . https://doi.org/10.1016/j.jstrokecerebrovasdis.2020.105152

http://hdl.handle.net/10138/332692

https://doi.org/10.1016/j.jstrokecerebrovasdis.2020.105152

cc_by_nc_nd

acceptedVersion

Downloaded from Helda, University of Helsinki institutional repository.

This is an electronic reprint of the original article.

This reprint may differ from the original in pagination and typographic detail.

Please cite the original version. 


\section{Localization and expression of sirtuins 1, 2, 6 and plasticity-related proteins in the recovery period after a photothrombotic stroke in mice}

Svetlana Demyanenko ${ }^{1}$, Elena Gantsgorn ${ }^{2}$, Stanislav Rodkin ${ }^{1}$, Svetlana Sharifulina ${ }^{3}$

1. Laboratory of Molecular Neurobiology, Academy of Biology and Biotechnology, Southern Federal University, pr. Stachki 194/1, Rostov-on-Don, 344090, Russia

2. Department of Pharmacology and Clinical Pharmacology, Rostov State Medical University, st. Nakhichevansky 29, Rostov-on-Don, 344022, Russia

3. Neuroscience Center, HiLife, University of Helsinki, Haartmaninkatu 8, P.O. Box 63 FI00014, Helsinki, Finland

E-mail addresses:

Svetlana Demyanenko: svdemyanenko@sfedu.ru

Elena Gantsgorn: gantsgorn@inbox.ru

Stanislav Rodkin: rodkin_stas@ mail.ru

Svetlana Sharifulina: svetlana.sharifulina@helsinki.fi

ORCID:

Svetlana Demyanenko: 0000-0002-4245-0427

Elena Gantsgorn: 0000-0003-0627-8372

Stanislav Rodkin: 0000-0003-4036-5410

Svetlana Sharifulina: 0000-0001-9841-5789

Corresponding author:

Svetlana Demyanenko, $\mathrm{PhD}$

Senior Researcher,

Laboratory of Molecular Neurobiology,

Academy of Biology and Biotechnology,

Southern Federal University,

prospect Stachki 194/1,

Rostov-on-Don, 344090 Russia

e-mail: demyanenkosvetlana@gmail.com

tel: $+7-8632-433111$

fax: $+7-863-2230837$ 


\begin{abstract}
Sirtuins, class III histone deacetylases, are involved in the regulation of tissue repair processes and brain functions after a stroke. The ability of some isoforms of sirtuins to circulate between the nucleus and cytoplasm may have various pathophysiological effects on the cells. In present work, we focused on the role of non-mitochondrial sirtuins SIRT1, SIRT2, and SIRT6 in the restoration of brain cells following ischemic stroke. Here, using a photothrombotic stroke (PTS) model in mice, we studied whether local stroke affects the level and intracellular localization of SIRT1, SIRT2, and SIRT6 in neurons and astrocytes of the intact cerebral cortex adjacent to the ischemic ipsilateral hemisphere and in the analogous region of the contralateral hemisphere at different time points during the recovery period after a stroke. We evaluated the co-localization of sirtuins with growth-associated protein-43 (GAP-43), the presynaptic marker synaptophysin (SYN) and acetylated $\alpha$-tubulin (Ac- $\alpha$-Tub), that are associated with brain plasticity and are known to be involved in brain repair after a stroke. The results show that during the recovery period, an increase in SIRT1 and SIRT2 levels occurred. The increase of SIRT1 level was associated with an increase in synaptic plasticity proteins, whereas the increase of SIRT2 level was associated with an acetylated of $\alpha$-tubulin, that can reduce the mobility of neurites. SIRT6 co-localized with GAP-43, but not with SYN. Moreover, we showed that SIRT1, SIRT2, and SIRT6 are not involved in the PTS-induced apoptosis of penumbra cells. Taken together, our results suggest that sirtuins functions differ depending on cell type, intracellular localization, specificity of sirtuins isoforms to different substrates and nature of post-translational modifications of enzymes.
\end{abstract}

Key words: histone deacetylases; sirtuins; stroke; brain regeneration; GAP-43, synaptophysin, tubulin acetylation

\title{
Introduction
}

Sirtuins belong to III histone deacetylases. The activity of sirtuins requires nicotinamide adenine dinucleotide $(\mathrm{NAD}+)$, which makes these enzymes sensitive to metabolic and redox changes (Khoury et al., 2018). Unlike other deacetylases that hydrolyze acetyl-lysine residues, sirtuins deacetylate lysine residues and hydrolyze NAD. Sirtuins are named after protein Sir2, which modulates the lifespan of Saccharomyces cerevisiae (Kaeberlein et al., 1999). Seven sirtuins, SIRT 1-7, have been identified in mammals. SIRT1 and SIRT6 are mainly localized in the nuclei of cells, SIRT7, in the nucleoli, SIRT3, SIRT4 and SIRT5 are mitochondrial proteins, and SIRT2 is in the cytoplasm (Michishita et al., 2005). Sirtuins deacetylate various substrates, such as transcription 
factors, cell metabolism enzymes, and histones. They are involved in the regulation of many biological processes, including metabolism, cell growth, apoptosis and autophagy, as well as in the genetic control of aging (Ham and Raju, 2017).

Although evidence is accumulating in support of the neuroprotective role of SIRTs in ischemic stroke (Khoury et al., 2018; Conti et al., 2017), the function of the different sirtuin isoforms of sirtuins needs further investigation. The ability of some sirtuin isoforms of sirtuins to circulate between the nucleus and cytoplasm with different pathophysiological consequences for the cell requires a more detailed study of the cellular redistribution of sirtuins. In present study, we focused on the role of non-mitochondrial sirtuins SIRT1, SIRT2, and SIRT6 in the restoration of brain cells during the recovery period following ischemic stroke. Unlike the earlier stages of a stroke, the recovery period is poorly understood. Using a photothrombotic stroke model in mice, we studied whether local stroke affects the level and intracellular localization of SIRT1, SIRT2, and SIRT6 in neurons and astrocytes of the intact cerebral cortex adjacent to the infarct border (ischemic ipsilateral hemisphere) and in the analogous region of the contralateral hemisphere at the recovery period after a stroke. It is known that these adjacent brain regions are involved in the restoration of brain structure and functions after damage (Johansen-Berg et al, 2002; Seitz et al., 1998). To identify the molecular targets of different sitruin isoforms, we evaluated their colocalization with growth-associated protein-43 (GAP-43), the presynaptic marker synaptophysin (SYN) and acetylated $\alpha$-tubulin (Ac- $\alpha$-Tub), that are associated with brain plasticity and are known to be involved in brain repair after a stroke (Carmichael ST, 2005; Fletcher TL et al., 1991; Ng and Tang, 2015).

The results show that during the recovery period, an increase in SIRT1 and SIRT2 is observed, but with opposite functional consequences. The increase of SIRT1 level was associated with an increase in the expression of markers of synaptogenesis and neurite growth, whereas the increase of SIRT2 level was associated with an acetylation of $\alpha$-tubulin, that can reduce the mobility of neurites. SIRT6 co-localized with GAP-43, but not with SYN. SIRT1, SIRT2, and SIRT6 did not participate in the apoptosis of penumbra cells after photothrombotic stroke (PTS) in mice, despite the elevated levels of the cytoplasmic form of SIRT1.

\section{Materials and Methods}

\section{Chemicals}

Polyvinylidene difluoride (PVDF) membranes, blocking buffer (TBS 1\% Casein Blocker), and Clarity Western ECL Substrate were purchased from Bio-Rad (Moscow, Russia). All other reagents were purchased from Sigma-Aldrich-Rus (Moscow, Russia) unless otherwise noted. 


\section{Animals}

Adult (14-15week-old) male CD- 1 outbred mice (20-25 g), kept in groups of 4-5 mice with free access to food and water at 12 light/12 dark cycle, were used for the photothrombotic infarction of the cerebral cortex (in vivo model of ischemic stroke). The animal holding room was maintained at $22-25^{\circ} \mathrm{C}$, and an air exchange rate of 18 changes per hour. Anesthesia was caused by intraperitoneal injection of chloral hydrate (23100, Sigma) dissolved in $0.9 \% \mathrm{NaCl}$ at a dose of 300 $\mathrm{mg} / \mathrm{kg}$ body weight in a volume of $0.25 \mathrm{ml}$. Body temperature was monitored by a rectal thermometer and maintained within $37 \pm 0.5{ }^{\circ} \mathrm{C}$ using an electric mat. All procedures were performed in compliance with the ARRIVE guidelines for animal research and EU Directive 2010/63/EU for animal experiments and local legislation for ethics of experiments on animals. The animal protocols used in this work were evaluated and approved by the Committee of Animal Care and Use of the Southern Federal University (Approval No. 08/2016). Randomization based on a single sequence of random assignments, known as simple randomization, was used to allocate subjects in the study with online randomization tool Research randomizer https://www.randomizer.org.

\subsection{Ischemic stroke model}

Local unilateral photothrombotic stroke (PTS) of the cerebral cortex was used in the study as a reproducible experimental model of ischemic stroke (Watson et al., 1985; Lee et al., 2006). In PTS, local laser irradiation induces photoexcitation of the injected photosensitizing dye Rose Bengal (RB) causing damage to no more than $20 \%$ of brain tissue. This is the maximal volume of tissue damage that a human stroke patient can survive. In addition, PTS has several advantages, such as low invasiveness, high animal survival; high reproducibility of the same localization and degree of damage; long-term sensorimotor deficiency, allowing the use of this model in the study of the long-term effects of stroke (Watson et al., 1985; Lee et al., 2007). The PTS procedure has been previously described (Demyanenko et al., 2018) Briefly, anesthesia was induced by i.p. injection of chloral hydrate $(300 \mathrm{mg} / \mathrm{kg})$. After the longitudinal incision of the skull skin, the periosteum was removed. A solution of the Rose Bengal photosensitizer (R4507) at the concentration of $15 \mathrm{mg} / \mathrm{mL}$ was introduced intraperitoneally at a dose of $10 \mu \mathrm{g} / \mathrm{g}$ of the animal weight. The hydrophilic photosensitizer Rose Bengal does not cross the blood-brain barrier and does not penetrate the cells, but accumulates in the vessels of the brain. Subsequent local laser irradiation causes photoexcitation 
of the dye, intensive generation of highly toxic singlet oxygen, oxidative damage to the endothelium and basement membrane, platelet aggregation and microvessel occlusion, which leads to ischemic damage and death of nearby neurons and glial cells. Five minutes after the introduction of the photosensitizer, the brain region near the sensorimotor cortex ( $2 \mathrm{~mm}$ lateral to the bregma) (Franklin and Paxinos 2008) was irradiated by a an LPM-532-50 laser (NPF Dilaz, Russia). The irradiation parameters were the following: wavelength of $532 \mathrm{~nm}$, intensity of $0.2 \mathrm{~W} / \mathrm{cm}^{2}$, beam diameter of $1 \mathrm{~mm}$, and duration of $15 \mathrm{~min}$. Control groups included sham-operated animals that were subjected to the same manipulations without the photosensitizer. The animals were decapitated under terminal anesthesia with the chloral hydrate (600 mg/kg, i.p.) 3, 7, 14 or 21 days after the PTS.

\subsection{Immunofluorescence staining and image analysis}

At 3, 4, 7, 14, and 21 days after PTS mice were deeply anesthetized with chloral hydrate and perfused transcardially with $10 \%$ formalin solution in PBS. After extraction, the brains were postfixed in formalin overnight, then placed in $20 \%$ sucrose in PBS for $48 \mathrm{~h}$ at $+4^{\circ} \mathrm{C}$. Using a Leica VT $1000 \mathrm{~S}$ vibratome (Germany) $20 \mu \mathrm{m}$ thick frontal sections were obtained (starting with $+2 \mathrm{~mm}$ and ending with $-4 \mathrm{~mm}$ from bregma), which were frozen in 2-methylbutane and stored at $-80{ }^{\circ} \mathrm{C}$. Antibody staining protocol was used as previously described (Demyanenko et al., 2018). Briefly, slices were washed in PBS, blocked in 5\% bovine serum albumin (BSA, A7906) with 0.3\% TritonX-100 in PBS for $1 \mathrm{~h}$ at room temperature and incubated with primary antibodies at $4^{\circ} \mathrm{C}$ overnight. Then, the slices were washed in PBS and incubated for $1 \mathrm{~h}$ in secondary antibodies. The following dilutions were used: rabbit Anti-Sirt1 (AV32386, Sigma), Anti-Sirt2 (S8447, Sigma), Anti-Sirt6 (S4322, Sigma) antibodies - 1:250; mouse Anti-Synaptophysin (S5768, Sigma), AntiGAP43 (NBP2-50052, Novus Biologicals), Anti-acetylated $\alpha$-tubulin (T7451, Sigma), AntiNeuron-Specific Enolase (NSE, SAB4200571, Sigma) Anti-NeuN (TA809952, Thermo Fisher Scientific) and Gfap (SAB4200571, Sigma) antibodies - 1:500; secondary anti-Rabbit CF488A (SAB4600045) and anti-mouse CF555 (SAB4600302) antibodies - 1:1000. After incubation, the sections were washed three times for 5 minutes in PBS and incubated for 1 hour with secondary Anti-Rabbit CF488A (SAB4600045, Sigma) and Anti-mouse CF555 (SAB4600302, Sigma) antibodies in a 1: 1000 dilution. Control coverslips without primary antibody staining were also included. After washing in PBS, sections were mounted on glass in $60 \%$ glycerol in PBS. Imaging was performed with a color CCD camera 5 MP (Jenoptik, FRG) attached to an Eclipse FN1 fluorescent microscope (Nikon, Japan). Three representative fields from each brain region per animal were digitally captured using an excitation wavelength of $490 \mathrm{~nm}$ and an emission 
wavelength of $525 \mathrm{~nm}$, and an excitation wavelength of $510 \mathrm{~nm}$ and an emission wavelength of $565 \mathrm{~nm}$ (Nikon, Japan).

Quantitative assessment of fluorescence of experimental and control preparations was carried out using 10-15 images acquired with the same camera settings as described previously (Demyanenko et al., 2020). Briefly, the corrected total cell fluorescence (CTCF) was calculated for estimation of the fluorescence $(\mathrm{CTCF}=$ Integrated Density $-($ Area of selected cell $\times$ Mean fluorescence of background readings)) (McCloy et al., 2014), analyzed at least 100 cells. To determine the localization of the protein in a cell CTCF was estimated in the regions of cytoplasm and nucleus. Threshold values were selected once and remained constant when processing all photos. Relative changes $\Delta \mathrm{I}$ in fluorescence were calculated in comparison with the control group as $\Delta \mathrm{I}=(\mathrm{Iex}-\mathrm{Ic}) / \mathrm{Ic}$, where Iex is the average value of the fluorescence intensity in the studied areas of the brain and Ic is the average value of the fluorescence intensity in the control samples. Data are presented as mean $\Delta \mathrm{I} \pm$ S.E.M.

The co-localization of sirtuins with synaptophysin, GAP43, acetylated $\alpha$-tubulin, the neuron markers (NSE or NeuN), the astrocytes marker (GFAP) and the nuclear marker Hoecsht33342 (10 $\mu \mathrm{g} / \mathrm{ml}$; blue signal) was evaluated using the Image J program (http://rsb.info.nih.gov/ij/) with the JACoP plugin (Bolte and Cordelières, 2006). The Manders coefficient M1, which reflects the fraction of pixels with a red signal (synaptophysin, acetylated tubulin, cell type and nuclear marker or TUNEL staining) containing a green signal (proteins of interest) relative to the total signal from the red channel (Manders et al., 1992), was calculated for the RGB images (1280×960 pixels).

No preliminary graphic editing was carried out to exclude distortion of the fluorescence intensity values. The regions of interest were blindly selected and analyzed. The analysis was performed on 3 images for each of 6-8 animals in the group. The values obtained were expressed as mean \pm S.E.M.

\subsection{Sample processing}

Cortical tissue sampling and preparation of protein extracts were done as described previously (Demyanenko et al., 2018). Briefly, mice under chloral hydrate anesthesia were transcardially perfused with saline at 3, 7, 14, and 21 days after PTS. After the decapitation, the brain was isolated on ice; the cortex was separated; the damaged brain tissue was isolated by a circular knife $4 \mathrm{~mm}$ in diameter; and then a ring of undamaged tissue adjacent to the irradiated area and similar region in the contralateral hemisphere were cut using a knife with a diameter of $8 \mathrm{~mm}$. The infarct and undamaged regions of ischemic ipsilateral hemisphere in PTS mice model were determine as described earlier (Demyanenko et al., 2018). The samples were homogenized on ice in 
Lysis Buffer from the CelLytic ${ }^{\mathrm{TM}}$ NuCLEAR ${ }^{\mathrm{TM}}$ Extraction Kit (NXTRACT, Sigma), which was supplemented by a mixture of inhibitors of proteases and phosphatases that are necessary for preservation of proteins and their phosphorylated forms and by benzonase nuclease that destroys nucleic acids. After the homogenization, the samples were centrifuged for $5 \mathrm{~min}$ at $10000-11000 \mathrm{~g}$ at $4^{\circ} \mathrm{C}$ using a Mikro 220R centrifuge (Hettich, Germany). Then, a supernatant that contained cytoplasmic proteins was collected and the nuclear proteins were extracted from the pellet that contained cell debris and nuclei using a Nuclear Extraction Buffer from the NXTRACT kit. For this, the pellet was resuspended and incubated for 15 min with this buffer. After that, lysate was centrifuged for $10 \mathrm{~min}$ at $20000-21000 \mathrm{~g}$ at $4^{\circ} \mathrm{C}$ using the same centrifuge. The obtained supernatant that contains nuclear proteins and the cytoplasmic fraction obtained earlier were frozen in liquid nitrogen and stored at $-80^{\circ} \mathrm{C}$.

\subsection{Western blotting}

Bradford Reagent (B6916, Sigma) was used to determine protein content in the protein extracts according to the manufacturer's recommendations for a Hitachi U-5100 spectrophotometer (Japan). Samples with 10-20 $\mu \mathrm{g}$ of protein in $15 \mu \mathrm{L}$ were subjected to electrophoretic separation by Laemmli's method in polyacrylamide gel (10-12.5\%) in the presence of sodium dodecyl sulfate using Mini-PROTEAN Tetra cell (Bio-Rad). For quantitative estimation of the proteins under study, ColorBurst Electrophoresis Marker (C1992) was used. After the separation, the proteins were electrophoretically transferred to a PVDF membrane (162-0177, Bio-Rad). After the transfer, the protein membrane was washed in PBS and incubated for $1 \mathrm{~h}$ in a blocking buffer (TBS 1\% Casein Blocker, 161-0782, Bio-Rad). After washing in PBS, the membrane was incubated overnight at $4^{\circ}$ $\mathrm{C}$ with primary antibodies. The following dilutions of rabbit antibodies were used: 1:250 for AntiSirt1 (AV32386, Sigma), Anti-Sirt2 (S8447, Sigma), Anti-Sirt6 (S4322, Sigma), $\gamma$-Tubulin (SAB4503045, Sigma) and 1:1000 for mouse antibodies against $\beta$-actin (A5441). After the incubation, the membrane was washed in a Tris buffer (TTBS, $10 \mathrm{mM}$ Tris buffered saline $\mathrm{pH}$, $0,1 \%$ Tween-20) and incubated with secondary antibodies anti-rabbit IgG-peroxidase at the dilution of 1:1000 (A6154) and peroxidase-labelled anti-mouse antibody (NIF825, Amersham) for $1 \mathrm{~h}$ at room temperature. Protein detection was performed using Clarity Western ECL Substrate solutions (Bio-Rad). To analyze chemiluminescence, a Fusion SL system (Vilber Lourmat, France) and Vision Capt program were used.

\subsection{TUNEL assay}


The "In Situ Cell Death Detection Kit, TMR red” (\#12156792910, Roche) was used for detection and quantification of apoptotic cell death and for determination of co-localization of apoptotic cells (red signal) with cells labeled with antibodies for target proteins studied (green signals) as described previously (Demyanenko et al., 2020). The sections were first incubated with the primary antibody to the target protein as described above, washed and treated with reagents from the Cell detection kit as recommended by the manufacturer and incubated $1 \mathrm{~h}$ with the secondary antibody Anti-Rabbit CF488A (SAB4600045; 1:1000) and Hoechst 33342 (10 $\mu \mathrm{g} / \mathrm{ml}$; blue signal) at $37^{\circ} \mathrm{C}$. The apoptotic index (AI) was calculated for Tunel-positive cells in the penumbra, the contralateral hemisphere and in the cortex of sham-operated animals around the entire perimeter of the micropreparation at a 10x magnification according to the formula:

$\mathrm{AI}=($ number of $\mathrm{TUNEL}-$ positive cells/total number of cells stained by Hoechst $33342) \times 100 \%$.

Additionally, the co-localization of the studied proteins (green signal) with the apoptosis marker (red signal) was evaluated using the Image J program (http://rsb.info.nih.gov/ij/) with the JACoP plugin. The Manders coefficient M1, which reflects the fraction of pixels with both red and green fluorescence in relation to the total signal from the red channel, was calculated for the RGB images $(640 \times 480)$. No preliminary graphic editing was carried out to exclude distortion of the fluorescence intensity values. The regions of interests were blindly selected and analyzed. The analysis was performed on 3 images for each of 5-7 animals in the group. The values obtained were expressed as mean \pm S.E.M.

\subsection{Statistical analysis}

The data obtained are presented as mean \pm S.E.M.; no less than three fields of view have been analyzed for each region of the brain (6 to 8 mice were studied). One-way analysis of variance (ANOVA) was used. Values of $p<0.05$ were considered significant.

\section{Results}

3.1 Change in the expression and localization of SIRT1 in neurons and astrocytes of the cerebral cortex of mice during the recovery period after a PTS

SIRT1 is the most studied sirtuin, its brain level is higher than in other organs (Michishita et al., 2005). SIRT1 is a nuclear protein, but the presence of two nuclear export signals (NES) and two 
nuclear localization signals (NLS) allows SIRT1 to move from the nucleus to the cytoplasm and vice versa (Tanno et al, 2007).
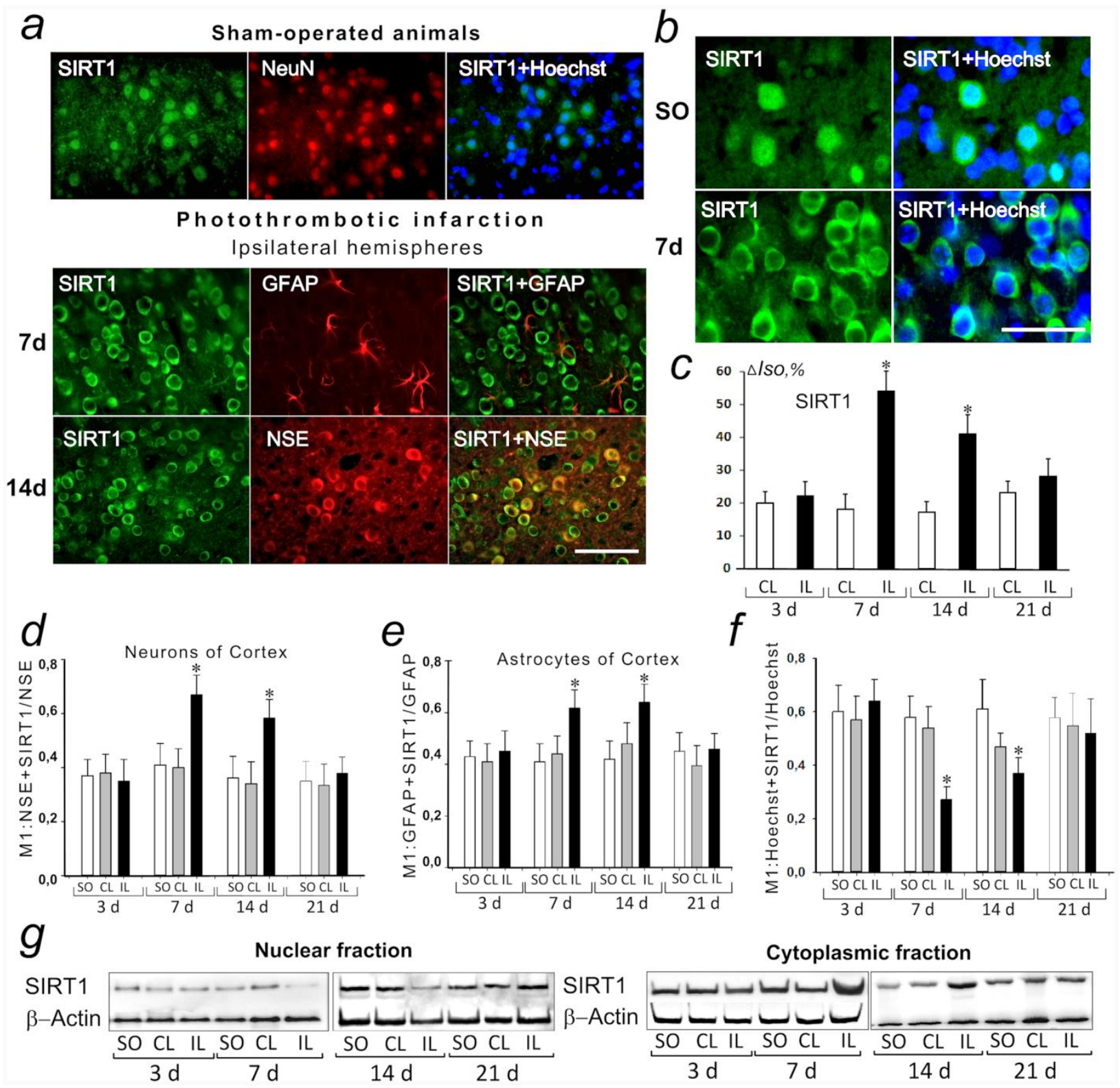

Fig. 1 Expression and localization of SIRT1 in mouse cortex cells. (a) Double immunofluorescence staining with antibodies against SIRT1 (green), neuron markers NeuN and NSE (red) and Hoechst 33342 (blue) showing the cortex of sham-operated mice and the damaged hemisphere at 7 and 14 days after PTS. The scale bar is $100 \mu \mathrm{m}$. (b) The immunofluorescence of SIRT1 in the cortex at higher magnification (60x). The scale bar is $30 \mu \mathrm{m}$. (c) Percentage of changes in the fluorescence intensity of SIRT1-positive cells in the damaged (IL) and contralateral (CL) hemispheres at different time points after PTS relative to sham-operated animals in $\%(\Delta \mathrm{Iso})$. (d, e) Average values of the co-localization coefficient M1, that reflects the fraction of pixels with a red signal (NSE or GFAP) containing also green signal (SIRT1), relative to the total signal from the red channel. (f) Average values of the co-localization coefficient M1, that reflects the fraction of pixels with a blue signal (Hoechst 33342, nuclear marker) containing the green signal (SIRT1), relative to the total signal from the blue channel. (g) Western blot membranes showing SIRT1 in the nuclear and cytoplasmic fractions of the tissue of the cortex of sham-operated animals at 3-21 days after the 
PTS in the damaged (IL) and the contralateral (CL) hemispheres. (ANOVA, $\mathrm{n}=5-8 ; * \mathrm{p}<0.05$ relative to sham-operated animals)

Our results showed that SIRT1 was present both in the nuclei and in the cytoplasm of neurons and astrocytes in the cortex of mice (Fig. 1a,b). IF analysis revealed a significant increase in the total SIRT1 immunoreactivity in the cortex of the ischemic ipsilateral hemisphere (Fig. 1a,c) compared to the control at 7 and 14 days after the PTS. Also we observe a significant rise in the colocalization of SIRT1 with neuron and astrocyte markers was observed (Fig. 1d,e). SIRT1 translocation to the cytoplasm and an increase of the relative abundance of cells that contained the protein only in the cytoplasm was observed for the neurons (Fig. 1b). The co-localization coefficient of SIRT1 and the Hoechst nuclear marker levels decreases by 54 and 39\% 7 and 14 days after the PTS, respectively (Fig. 1f). The results of the Western blot analysis also indicated an increase of SIRT1 level in the cytoplasmic fraction and a decrease of protein level in the nuclear fraction at 7 and 14 days after the PTS (Fig. 1g).

\subsection{SIRT1 expression is not associated with apoptosis}

The nuclear form of SIRT1 is known to suppress cell apoptosis caused by oxidative stress (Tanno et al., 2007), whereas the cytoplasmic localization of SIRT1 enhances cell apoptosis (Jin et al., 2007). After PTS only in penumbra cells near the infarct nucleus the apoptosis was observed. In penumbra, SIRT1 had a nuclear-cytoplasmic localization (Fig. 2a). We did not observe the colocalization of SIRT1 with apoptotically altered penumbra cells at 3 and 7 days after the PTS in the cerebral cortex of mice (Fig. 2a), although apoptosis of penumbra cells increased compared to sham-operated animals (Fig. 2b). 

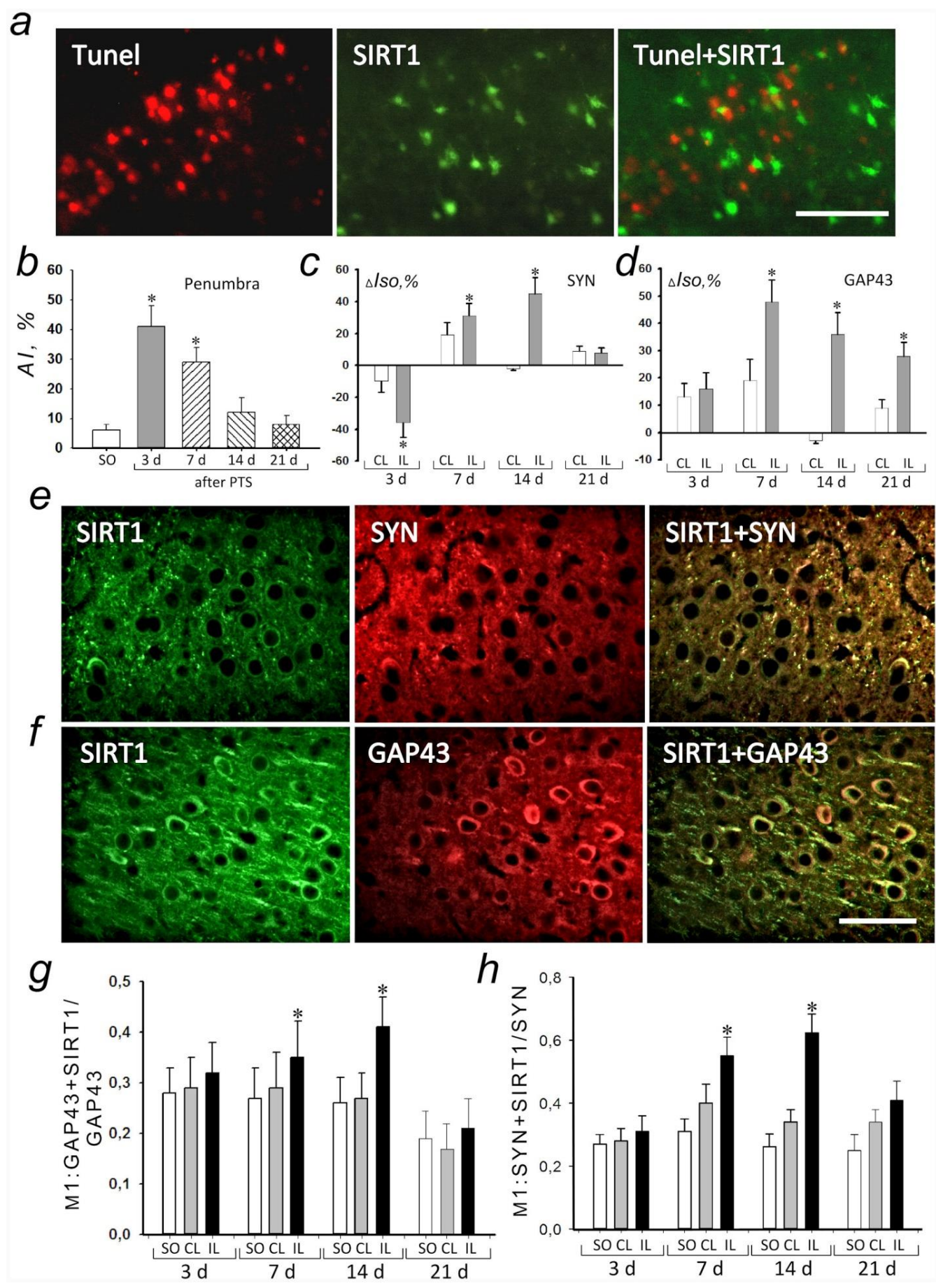

Fig.2 SIRT1 co-localization with apoptotic cells and plasticity-related proteins. (a) Typical fluorescence image of the penumbra at 7 days after PTS, sections were stained using the TUNEL method (red) to visualize apoptotic nuclei, SIRT1 (green) and the Hoechst 33342 cell nucleus marker (blue). The scale bar is $100 \mu \mathrm{m}$. (b) Changes in apoptotic index (AI, \%) in sham-operated animals (SO) and in penumbra at 3-21 days after PTS. (c, d) Percentage of changes in the fluorescence intensity of SYN (c) and GAP43 (d) in the damaged (IL) and contralateral (CL) hemispheres at different time points after the PTS relative to sham-operated animals ( $\triangle \mathrm{Iso})$. (e, f) Double staining with antibodies against SIRT1 (green), GAP43 (red) or synaptophysin (red) of the damaged mouse cortex 14 days after PTS. The scale bar is $100 \mu \mathrm{m} .(\mathrm{g}, \mathrm{h})$ Average values of the colocalization coefficient M1, that reflects the fraction of pixels with a red signal GAP43 (g) or synaptophysin (h) containing a green signal (SIRT1), relative to the total signal from the red channel. (ANOVA, $\mathrm{n}=5-8 * \mathrm{p}<0.05$ relative to sham-operated animals) 


\subsection{SIRT1 is associated with synaptic plasticity proteins}

Synaptophysin (SYN) and growth-associated protein 43 (GAP-43) are two important synapse-associated proteins. The presynaptic marker SYN is a synaptic vesicle protein that is involved in the regulation of synaptic transmission efficiency (Wheeler et al., 2002).

On the third day after PTS, we observe, a 36\% decrease in the SYN IF level in cortical cells was observed, but on day 7, the SYN expression in the intact cerebral cortex of the injuried hemisphere was $31 \%$ higher than in sham-operated animals and remained high up to 14 days. On day 21, the protein level did not differ from the control level (Fig. 2c).

GAP-43 is a protein associated with the growth of neurites during the development and regeneration of the nervous system and during the recovery period following ischemia (Benowitz and Routtenberg, 1997; Carmichael et al., 2005). GAP-43 is also present on the postsynaptic membrane (Stroemer et al., 1993) and, in addition to lengthening cell projections, is involved in a more complex setup of intercellular networks necessary for proper tissue regeneration (Gorup et al., 2015).

In the cells of the cortex of the intact region of the ipsilateral hemisphere of the mouse brain, the GAP-43 IF level was significantly $48 \%$ increased on the 7th day and remains high up to 21 days after PTS compared to sham- operated animals (Fig. 2c)

An increase of GAP-43 level in the brain after a stroke can be either a result of regeneration processes or a result of protein release from damaged axons at the early stages after PTS. The increase of the cytoplasmic SIRT1 levels in neurons at 7 and 14 days after PTS was correlated with the expression of SYN and GAP-43 in this period after PTS. In neurons ischemic hemisphere of mice, the increase of co-localization SIRT1 and SYN (Fig.2 c,e), as well as SIRT1 and GAP43 (Fig. 2 d,f), were observed at 7 and 14 days after PTS.

3.4 Changes in the expression and localization of SIRT2 in neurons and astrocytes of the cerebral cortex of mice during the recovery period after IPT

In the central nervous system, SIRT2 is the only sirtuin isoform with a mainly cytoplasmic localization, but it can temporarily move to the nucleus depending on the cell cycle (Vaquero et al., 2006). Our IF and WB analysis also indicate exclusively cytoplasmic localization of the enzyme in neurons (Fig. 3 a,d,c). In astrocytes, SIRT2 expression level was low (Fig. 3a). 


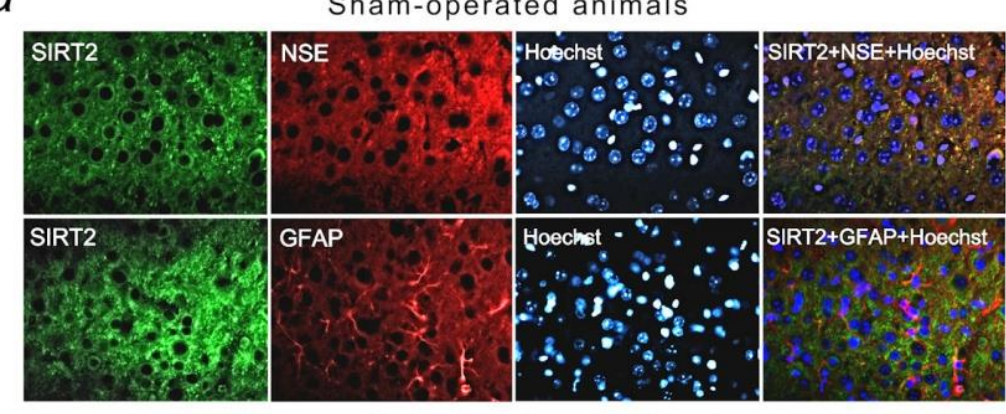

3 days after photothrombotic stroke

Contralateral hemispheres

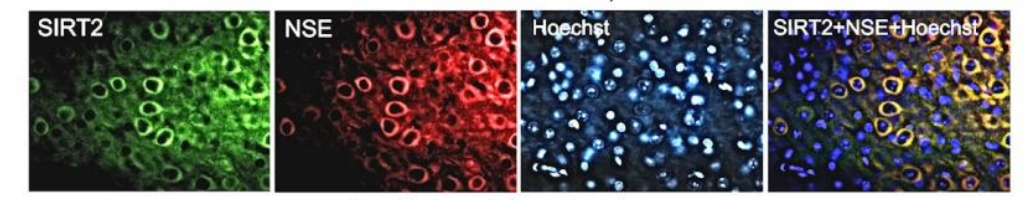

Ipsilateral hemispheres

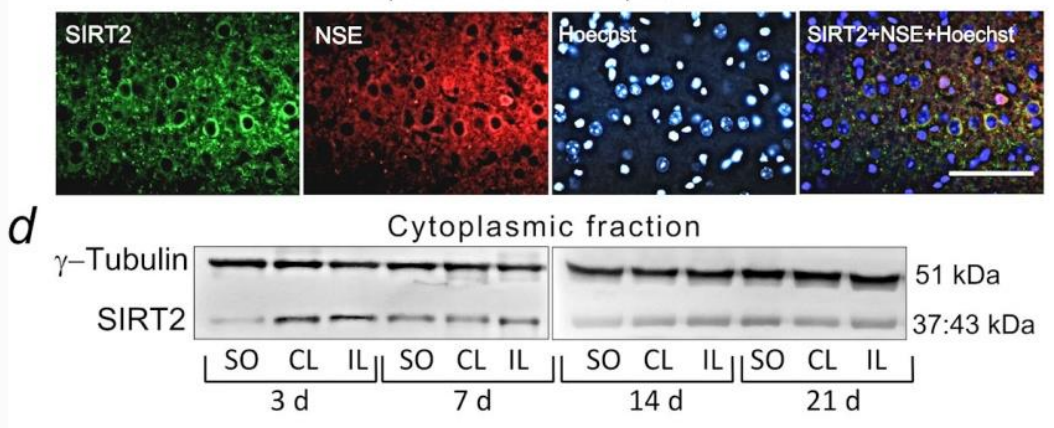

e

3 days after photothrombotic stroke Ipsilateral hemispheres

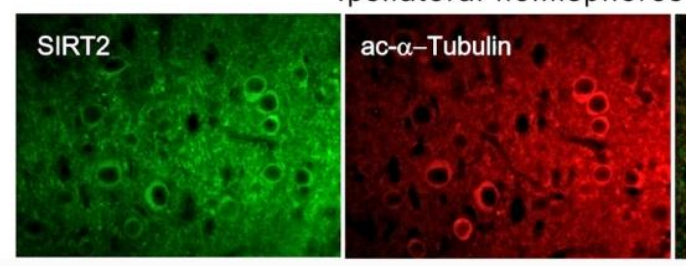

$b$

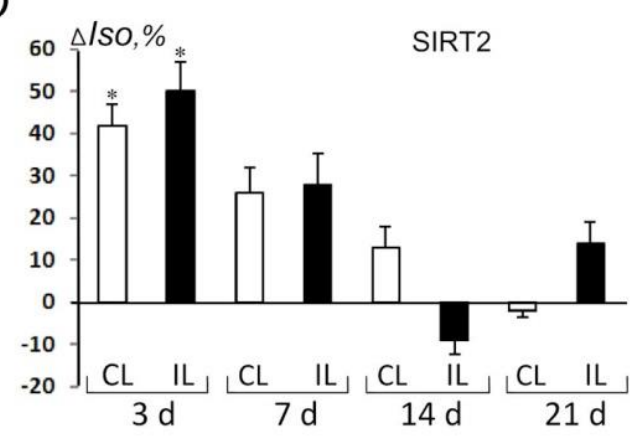

C
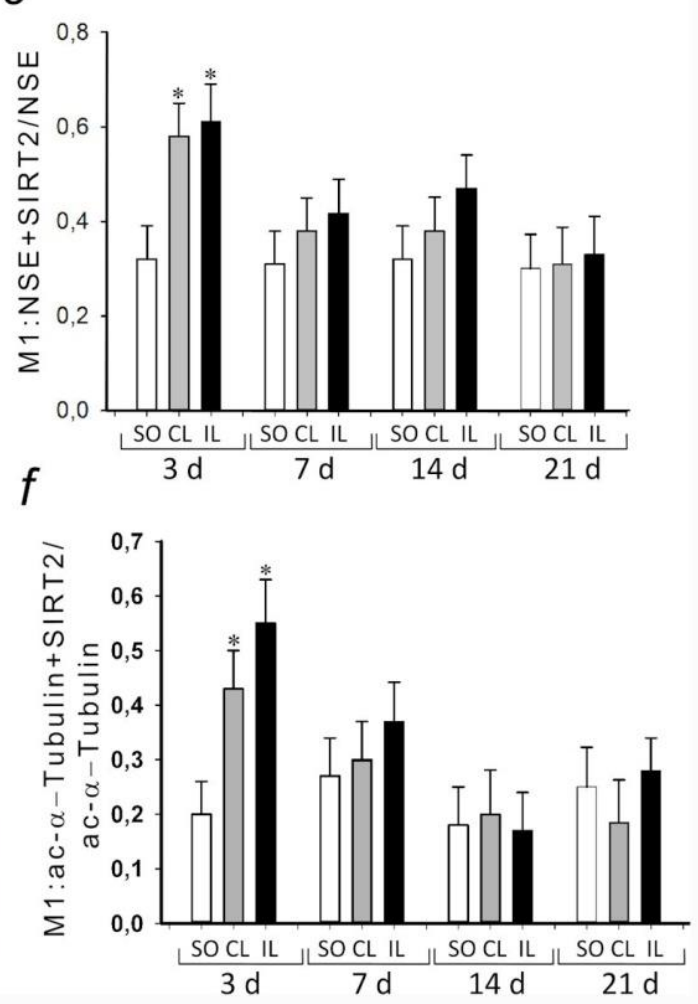

Fig. 3 Expression and localization of SIRT2 in mouse cortex cells. (a) Double immunofluorescence staining with antibodies against SIRT2 (green), the neuronal marker NSE and the astrocytes marker GFAP (red) and Hoechst 33342 (blue) of the cortex of sham-operated mice, damaged and contralateral hemispheres at 3 days after PTS. The scale bar is $100 \mu \mathrm{m}$. (b) Percentage changes in the fluorescence intensity of SIRT2-positive cells in the damaged (IL) and contralateral (CL) hemispheres at different times points after PTS relative to sham-operated animals in $\%$ ( $\Delta$ Iso). (c) Average values of the co-localization coefficient M1, reflecting the fraction of pixels with a red signal (NSE) containing a green signal (SIRT2), relative to the total signal from the red channel. (d) Western blot membranes presenting SIRT2 in the cytoplasmic fractions of the tissue of the cortex of sham-operated animals and 3-21 days after the PTS in the damaged (IL) or contralateral (CL) hemispheres. (e) Double staining with antibodies against SIRT2 (green) and acetylated $\alpha$-tubulin (red) showing the damaged cortex of mice 3 days after PTS. The scale bar is $50 \mu \mathrm{m}$ (f) Average values of the co-localization coefficient M1, reflecting the fraction of pixels with a red signal (ac- $\alpha-$ tubulin) containing the green signal (SIRT2), relative to the total signal from the red channel. (ANOVA, $\mathrm{n}=5-8 * \mathrm{p}<0.05$ relative to sham-operated animals)

At the early stages after occlusion of the middle cerebral artery (MCAO), an increase of the nuclear form of SIRT2 level was detected in mice and in the penumbra of stroke survivors (Xie et 
al., 2017). According to our research, at the early recovery period after PTS, there is no translocation of SIRT2 between the nucleus and the cytoplasm in neurons (Fig. 3a). However, we also noted an increase of protein immunoreactivity in neurons of the ipsilateral cortex, which was consistent in the observations in human patients in the early recovery period on the first day after a stroke (Xie et al., 2017), and, importantly, in the contralateral hemispheres of the mouse brains 3 days after PTS. This is indicated by both the IF analysis data (Fig. 3 a,b,c) and the results of a WB analysis (Fig. 3d).

$\alpha$-tubulin is known to be the substrate of SIRT2 in the cytoplasm (North et al., 2003). According to immunofluorescence analysis, an SIRT2 expression increase was associated with an increase of acetylated $\alpha$-tubulin (Ac- $\alpha$-tub) level. The colocalization of SIRT2 and Ac- $\alpha$-tub in the cortex of the damaged and contralateral hemispheres of the mouse brain increased 3 days after PTS (Fig. 3 e, f). No SIRT2 IF signal was detected in apoptotic cells.

3.5 Changes in the expression and localization of SIRT6 in neurons and astrocytes of the cerebral cortex of mice during the recovery period after PTS. SIRT6 binding to synapse-associated proteins

Little is known about SIRT6. In our study, we observed the expression of SIRT6 in neurons and astrocytes of the cerebral cortex of sham-operated animals, both in the nuclei and in the cytoplasm of cells (Fig. 4a). Both the expression and intracellular localization of SIRT6 did not significantly change after PTS. However, at 14 days after PTS, we observe an increase in SIRT6 co-localization with GAP43 in neurons of the cortex of the ischemic hemisphere of the mouse brain was observed (Fig. 4 b,c). We did not observe co-localization of SIRT6 with apoptotic cells, similarly to SIRT1 and SIRT2. This indicates that these histone acetyltransferases are not involved in the PTS-induced apoptosis of penumbra cells. 

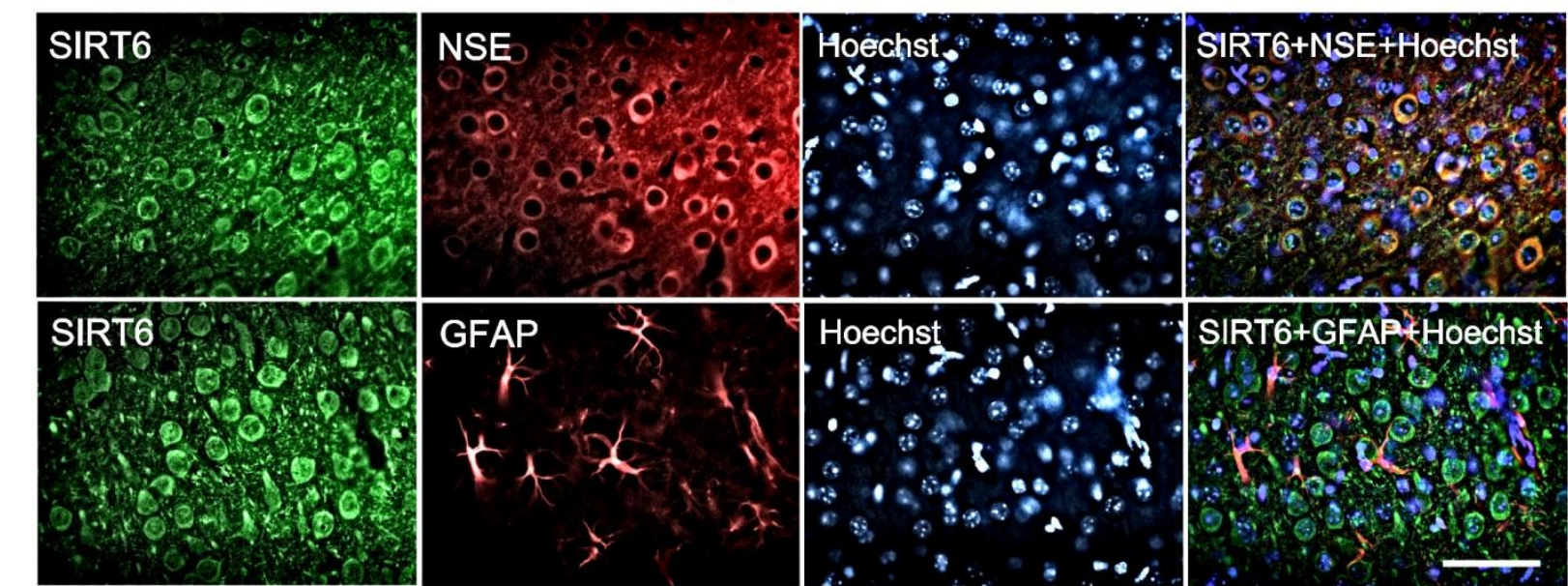

$b$

\section{4 days after photothrombotic stroke \\ Ipsilateral hemispheres}
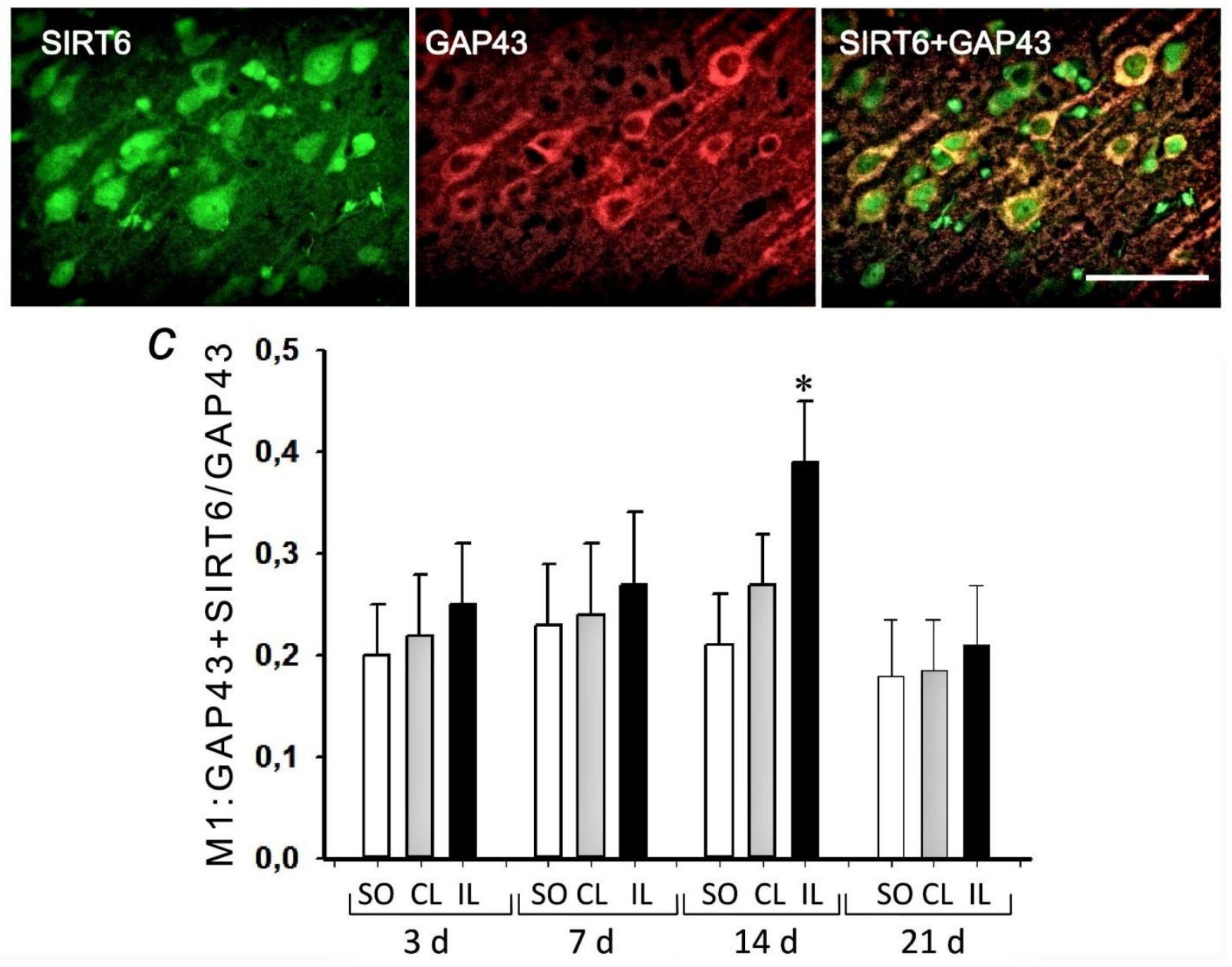

Fig. 4 Expression and localization of SIRT6 in mouse cortex cells. (a) Double immunofluorescence staining with antibodies against SIRT6 (green), the neuronal marker NSE, the astrocytes marker GFAP (red) and Hoechst 33342 (blue) in the cortex of sham-operated mice. The scale bar is 100 $\mu \mathrm{m}$. Double staining with antibodies against SIRT2 (green) and acetylated $\alpha$-tubulin (red) of the damaged cortex of mice 3 days after PTS. The scale bar is $100 \mu \mathrm{m}$. (b) Double staining with antibodies against SIRT6 (green) and GAP43 (red) of the damaged cortex of mice 14 days after PTS. The scale bar is $100 \mu \mathrm{m}$. (c) Average values of the co-localization coefficient M1, that reflects the fraction of pixels with a red signal (GAP43) containing the green signal (SIRT6), relative to the total signal from the red channel. (ANOVA, $\mathrm{n}=5-8 ; * \mathrm{p}<0.05$ relative to sham-operated animals) 


\section{Discussion}

There is no doubt that sirtuins are modulators of many biological processes under both normal and pathological conditions of the body and, in particular, under ischemic stroke.

SIRT1 has shown neuroprotective effects in numerous studies on models of ischemic stroke, brain injury, and neurodegenerative diseases (She et al., 2017; $\mathrm{Ng}$ et al., 2015). In SIRT1 knockout mice, an increase in infarct size has been observed after MCAO (Hernandez-Jimenez et al., 2013), while mice overexpressing SIRT1 were more resistant to ischemia (Hattori et al., 2015). SIRT1 activators reduce the size of infarct ( $\mathrm{Li}$ et al., 2012).

An increase of SIRT1 expression level in the penumbra of the cerebral cortex of mice was shown up to 7 days after MCAO (Hernández-Jiménez et al. 2013). In the PTS model, an increase of SIRT1 expression level was observed up to 14 days in both neurons and astrocytes of intact areas of the cerebral cortex of mice.

Since SIRT1 deacetylates histones and various transcription factors (She et al., 2017; Khoury et al., 2018) and may have chaperone-like activity (Pfister et al., 2008), its subcellular localization should affect its function. It is known that subcellular localization of SIRT1 can change during brain development and in response to physiological and pathological stimuli (Tanno et al., 2007; Hisahara et al., 2008). SIRT1 localized in the nucleus has been shown to prevent apoptosis by deacetylation of p53 (Luo et al., 2001), FOXO (Brunet et al., 2004) and Ku70 (Cohen et al. Al., 2004). Not much is known about the functions of the cytoplasmic form of SIRT1. SIRT1 localized in the cytoplasm has been shown to enhance caspase-dependent cell apoptosis (Jin et al., 2007). However, our results show that SIRT1 translocation into the cytoplasm was not associated with apoptosis of cells adjacent to the damage nucleus, 7 days after focal ischemia caused by photothrombosis of the cerebral cortex,. In contrast, cytoplasmic SIRT1 was associated with synaptic plasticity proteins SYN and GAP43.

Ischemic stroke is the main cause of disability worldwide after which surviving neurons in the periinfarction region form new connections through the growth of neurites and synaptogenesis as part of the recovery process [Ueno et al., 2012]. Synaptophysin (SYN) is a marker of synaptic contacts and synaptogenesis (Fletcher T.L. et al., 1991). This is a protein of the membranes of synaptic vesicles in the presynaptic terminals of neurons, and it is involved in the regulation of the formation of vesicles and their exocytosis. SYN levels are used as a marker for synaptic vesicle counts and synaptogenesis, as well as a marker for synaptic transmission efficiency (Wheeler et al., 2002; Gordon 2011 et al., 2011). SYN expression reflects the plasticity of the nervous system during ischemic damage, and the restored expression of synaptophysin indicates recovery from stroke (Zhang et al. 2017; Fang et al., 2010). Most likely with the growth of apoptosis level of the penumbra cells at 3 and 7 days after the PTS, protein expression and synaptic processes in the areas adjacent to the damage nucleus are slowed down; therefore, we observe a decrease in the SYN level in the relatively intact cortex of the ipsilateral hemisphere after the PTS. However, already at the 7th day, SYN expression level is restored and becomes even higher than in animals without PTS. Coinciding with the increase of SYN level the level of cytoplasmic SIRT1 increases at 7 and 14 days after the PTS.

At the same time, the co-localization of SIRT1 with another marker of regeneration GAP43 increases. In rodents, after transient middle cerebral artery occlusion (tMCAo), GAP43 is present at an early stage in the site of ischemic lesion, followed by expression in the penumbra (Li et al., 1998), suggesting an early activation of GAP43 to preserve and regenerate tissues. With constant MCAO, where the tissue is more severely and irreversibly damaged, GAP-43 is absent in the core of the infarct but its expression increases in the penumbra, reaching a maximum on day 7 (Miyake et al., 2002). The PTS model is characterized by rapid vascular damage and cell death in the infarct, which makes the formation of a wide penumbra impossible (Lee et al., 2007; Uzdensky et al., 
2017). This might be the reason we are observing an increase in the level of GAP43 in the relatively intact region of the ipsilateral hemisphere starting from the 7th day after the PTS. The delayed increase in GAP43 after PTS may reflect the time required for the spreading of the neuronal damage to larger sections of the peri-infarction space and the time delay before the death of neurons expressing GAP43 with the release of protein into the extracellular space, as well as the time required for the complex setup of intracellular and intercellular networks necessary for proper tissue regeneration. In our study, the expression of GAP43 remains high until 21 days after PTS with a maximum at 7 days. In this case, a co-localization of the cytoplasmic form of SIRT1 and GAP43 is observed on the 7th and 14th day after ischemia, which indicates the participation of SIRT1 in the regulation of tissue repair and brain function after a stroke. Moreover, the cytoplasmic localization may be an important determinant of the effect of SIRT1 on neuroplasticity. It was previously shown that resveratrol stimulated neurite growth and in vitro nerve cell synaptogenesis (Tang et al., 2017). It was shown that cytoplasmic SIRT1 increased neurite growth caused by nerve growth factor (NGF), while SIRT1 or SIRT1-siRNA inhibitors significantly inhibited it (Sugino et al., 2010).

SIRT2 is the closest homolog of SIRT1. It is been previously reported that in the ischemic brain, SIRT2 is activated in myelin-rich areas of the brain, mainly in oligodendrocytes, while its expression has not been detected in astrocytes, microglia, or neurons (Krey et al., 2015). In our study, SIRT2 is found in the cytoplasm of neurons, but not in the astrocytes of the mouse cortex, which is consistent with the data obtained by Maxwell et al. in 2011.

In a recent study, Xie et al. (2017) showed that inhibition of SIRT2 in the brain has a neuroprotective effect in the tMCAO mouse model. Moreover, the authors report a high expression of SIRT2 in the cytoplasm of neurons, but not in microglia or astrocytes. In response to ischemia, SIRT2 translocates to the nuclei of the neurons (Xie et al., 2017). In studies using a differentiated PC12 cell line, Nie et al. (2014) showed that in response to oxidative stress, SIRT2 levels increase leading to apoptosis caused by oxidative stress. Moreover, overexpression of the cytoplasmic form of SIRT2 in cerebellar granule neurons or HT22 cells can cause apoptosis (Pfister et al., 2008). In our study, we observed an increase in the level of cytoplasmic SIRT2 in the neurons of the cortex of the damaged and, more interestingly, intact cerebral hemispheres of mice at 3 days after PTS. However, this increase in SIRT2 levels in the cytoplasm of neurons was not associated with apoptosis of penumbra cells at these times. It is known that not only Sirt2 mRNA, but also Sirt2 protein isoforms respond differently to ischemia (Krey et al., 2015). Thus, the expression of the main cytoplasmic isoform (SIRTv2) decreases after MCAO compared to sham-operated mice, and v1 isoform (SIRTv1) is actively expressed both in the ischemic (ipsilateral) and non-ischemic (contralateral) hemispheres of the brain compared to sham-operated animals, that we also observe on the third day after PTS. Despite the fact that most studies indicate the pathological role of SIRT2 in brain ischemia (She et al., 2017; Xie et al., 2017), in our opinion, the function of SIRT2 in the ischemic brain is much more complicated than simply pathological or neuroprotective and depends on the cellular and intracellular localization of different isoforms of the enzyme, its phosphorylation level and the type of substrate.

In the cytoplasm, both the NAD + -dependent SIRT2 and the NAD + -independent HDAC6 class II are known to play an important role in the regulation of microtubule dynamics by deacetylation of $\alpha$-tubulin with lysine 40 (North et al., 2003). SIRT2 and HDAC6 are likely to deacetylate $\alpha$-tubulin both in combination with each other (Nahhas et al., 2007) and separately (North et al., 2003). Acetylation of $\alpha$-Tub increases microtubule stability, improves the interaction between $\alpha$-tubulin and motor proteins, which facilitates microtubule-based transport (Magiera and Janke 2014). The microtubule-based transport is necessary for numerous processes occurring in neurons, such as neurotransmission, axon germination and regeneration, synaptogenesis, etc. (Liu et al., 2012). Earlier, we showed that PTS causes a significant decrease of the level of the acetylated form of $\alpha$ tubulin in the cerebral cortex of mice up to 7 days after injury (Demyanenko et al., 2019). In this case, the administration of the selective HDAC6 inhibitor tubastatin A restored the level of Ac- $\alpha-$ Tub to control values ADemyanenko et al., 2019; Wang et al., 2016). Our study shows the high co- 
localization of SIRT2 and the acetylated tubulin. This is probably due to the fact that SIRT2 involvement is limited by perinuclear microtubules, and HDAC6 activation leads to general hypoacetylation of the microtubule network throughout the cell (Skoge and Ziegler, 2016). Perinuclear microtubules surround the nucleus, linking it to the periphery of the cell. In neurons, hypoacetylated perinuclear microtubules are involved in nuclear translocation of proteins or mitochondria (Stiess and Bradke, 2011). This specificity of SIRT2 is probably achieved due to the smaller protein size compared to HDAC6 or it could have easier access through transient microtubule lattice openings between protofilaments (Skoge and Ziegler, 2016). In addition, it was shown that only the specific isoform SIRT2, SIRT2.3, deacetylates $\alpha$-tubulin in the brain and spinal cord of old mice (Maxwell et al., 2011). Thus, a decrease in $\alpha$-tubulin acetylation after stroke is likely to be associated with activity HDAC6, rather than with SIRT2 activity.

SIRT6 is the least studied non-mitochondrial sirtuin. SIRT6 immunoreactivity was detected both in neurons and in astrocytes (Favero et al., 2014), that correlates with our data obtained. SIRT6 is believed to act on acetylated lysine residues such as $\mathrm{H} 3 \mathrm{~K} 9 \mathrm{ac}$ and $\mathrm{H} 3 \mathrm{~K} 56 \mathrm{ac}$, which causes repression of genes associated with aging (Tennen et al., 2011). However, the role of SIRT6 in ischemia is largely unclear and controversial. On the one hand, SIRT6 can protect the brain from ischemic reperfusion (I / R) damage by suppressing oxidative stress by activating NRF2 (Zhang et al., 2017). On the other hand, overexpression of SIRT6 in cultured neurons led to decreased viability and increased cell necrosis under oxidative stress caused by a lack of oxygen and glucose (Shao et al., 2016). We did not observe protein IF signal in apoptotic penumbra cells. This is likely due to the ability of SIRT6 to repair DNA (Tennen et al., 2011; Mao et al., 2011).

It was previously shown that SIRT6 is contained in a significant amount in the synaptosomal fractions of mouse cortex and hippocampal neurons (Cardinale et al., 2015). However, we did not find a co-localization of SIRT6 with synaptophysin marker of presynaptic vesicles after PTS. However, the protein was co-expressed with a marker of axonogenesis and postsynaptic membranes - GAP43 protein on the 14th day after ischemia. Whether this is due to the fact that SIRT6 can be a part of the multi-protein complex of the postsynaptic membrane (Cardinale et al., 2015) or that the protein is involved in the regulation of neurite growth during the recovery of brain tissue after a stroke, needs to be studied in more detail.

\section{Conclusion}

There is no doubt that sirtuins are involved in the regulation of tissue repair processes and brain functions after a stroke. However, in light of the present and previous results, it cannot be said whether the effect of sirtuins on cell survival and repair following stroke is unequivocally negative or positive. Their functions seem very complex and they differ depending on the cell type, intracellular localization, the specificity of the different isoforms of sirtuins to different substrates, and the nature of post-translational modifications of enzymes. Thus, further experimental studies in vivo and in vitro of the cellular and intracellular redistribution of sirtuins will give a better understanding of the molecular mechanisms underlying the restoration of the functions of neurons and astrocytes after ischemic damage, which may help to identify new targets for the treatment of stroke.

\section{Declarations}

\section{Funding}

The work was supported by Russian Science Foundation, [grant \#18-15-00110].

Conflicts of interest/Competing interests (include appropriate disclosures)

The authors declare no conflict of interests. 


\section{Ethics approval}

The submitted work is original and should not have been published elsewhere and not submitted to other journals; no plagiarism.

\section{Consent to participate}

The study did not involve human participants

\section{Consent for publication}

The study did not involve human participants

1. Benowitz LI, Routtenberg A (1997) GAP-43: an intrinsic determinant of neuronal development and plasticity. Trends Neurosci 20(2):84-91. https://doi.org/10.1016/S01662236(96)10072-2

2. Bolte S, Cordelières FP (2006) A guided tour into subcellular colocalization analysis in light microscopy. J Microsc 224(Pt 3):213-232. https://doi.org/10.1111/j.13652818.2006.01706.x

3. Brunet A, Sweeney LB, Sturgill JF, Chua KF, Greer PL, Lin Y, Tran H, Ross SE, Mostoslavsky R, Cohen HY, Hu LS, Cheng HL, Jedrychowski MP, Gygi SP, Sinclair DA, Alt FW, Greenberg ME (2004) Stress-dependent regulation of FOXO transcription factors by the SIRT1 deacetylase. Science 303(5666):2011-5. https://doi.org/10.1126/science.1094637

4. Cardinale A, de Stefano MC, Mollinari C, Racaniello M, Garaci E, Merlo D (2015) Biochemical characterization of sirtuin 6 in the brain and its involvement in oxidative stress response. Neurochem Res 40(1):59-69. https://doi.org/10.1007/s11064-014-1465-1

5. Carmichael ST, Archibeque I, Luke L, Nolan T, Momiy J, Li S (2005) Growth-associated gene expression after stroke: evidence for a growth-promoting region in peri-infarct cortex. Exp Neurol 193(2):291-311. https://doi.org/10.1016/j.expneurol.2005.01.004

6. Cohen HY, Lavu S, Bitterman KJ, Hekking B, Imahiyerobo TA, Miller C, Frye R, Ploegh H, Kessler BM, Sinclair DA (2004) Acetylation of the C terminus of Ku70 by CBP and PCAF controls Bax-mediated apoptosis. Mol Cell 13(5):627-38. https://doi.org/10.1016/s1097-2765(04)00094-2

7. Conti V, Forte M, Corbi G, Russomanno G, Formisano L, Landolfi A, Izzo V, Filippelli A, Vecchione C, Carrizzo A (2017) Sirtuins: possible clinical implications in cardio and cerebrovascular diseases. Curr Drug Targets 18(4):473-484. https://doi.org/10.2174/1389450116666151019095903

8. Demyanenko S, Berezhnaya E, Neginskaya M, Rodkin S, Dzreyan V, Pitinova M (2019) Class II histone deacetylases in the post-stroke recovery period-expression, cellular, and 
subcellular localization-promising targets for neuroprotection. $\mathrm{J}$ Cell Biochem 120(12):19590-19609. https://doi.org/10.1002/jcb.29266

9. Demyanenko S, Neginskaya M, Berezhnaya E (2018) Expression of class I histone deacetylases in ipsilateral and contralateral hemispheres after the focal photothrombotic infarction in the mouse brain. Transl Stroke Res 9(5):471-483. https://doi.org/10.1007/s12975-017-0595-6

10. Demyanenko SV, Dzreyan VA, Neginskaya MA, Uzdensky AB (2020) Expression of histone deacetylases HDAC1 and HDAC2 and their role in apoptosis in the penumbra induced by photothrombotic stroke. Mol Neurobiol 57(1):226-238. https://doi.org/10.1007/s12035-019-01772-w

11. Fang S, Yan B, Wang D, Bi X, Zhang Y, He J, Xu H, Yang Y, Kong J, Wu J, Li XM (2010) Chronic effects of venlafaxine on synaptophysin and neuronal cell adhesion molecule in the hippocampus of cerebral ischemic mice. Biochem Cell Biol 88(4):655-63. https://doi.org/10.1139/010-015

12. Favero G, Rezzani R, Rodella LF (2014) Sirtuin 6 nuclear localization at cortical brain level of young diabetic mice: an immunohistochemical study. Acta Histochem 116(1):2727. https://doi.org/10.1016/j.acthis.2013.08.006

13. Fletcher T.L., Cameron P., De Camilli P., Banker G (1991) The distribution of synapsin I and synaptophysin in hippocampal neurons developing in culture. J. Neurosci 11(6):16171626. https://doi.org/10.1523/JNEUROSCI.11-06-01617.1991

14. Franklin KBJ, Paxinos G (2008) The Mouse Brain in Stereotaxic Coordinates. 3rd ed. Amsterdam: Elsevier Academic Press

15. Gordon SL, Leube RE, Cousin MA (2011) Synaptophysin is required for synaptobrevin retrieval during synaptic vesicle endocytosis. J Neurosci 31(39):14032-14036. https://doi.org/10.1523/JNEUROSCI.3162-11.2011

16. Gorup D, Bohaček I, Miličević T, Pochet R, Mitrečić D, Križ J, Gajović S (2015) Increased expression and colocalization of GAP43 and CASP3 after brain ischemic lesion in mouse. Neurosci Lett 597:176-82. https://doi.org/10.1016/j.neulet.2015.04.042

17. Ham PB 3rd, Raju R (2017) Mitochondrial function in hypoxic ischemic injury and $\begin{array}{llll}\text { influence of } \quad \text { aging. Prog Neurobiol } & \text { 157:92-116. }\end{array}$ https://doi.org/10.1016/j.pneurobio.2016.06.006

18. Hattori Y, Okamoto Y, Nagatsuka K, Takahashi R, Kalaria RN, Kinoshita M, Ihara M (2015) SIRT1 attenuates severe ischemic damage by preserving cerebral blood flow. Neuroreport 26(3):113-7. https://doi.org/10.1097/WNR.0000000000000308 
19. Hernández-Jiménez M, Hurtado O, Cuartero MI, Ballesteros I, Moraga A, Pradillo JM, McBurney MW, Lizasoain I, Moro MA (2013) Silent information regulator 1 protects the brain against cerebral ischemic damage. Stroke 44(8):2333-7. https://doi.org/10.1161/STROKEAHA.113.001715

20. Hisahara S, Chiba S, Matsumoto H, Tanno M, Yagi H, Shimohama S, Sato M, Horio Y (2008) Histone deacetylase SIRT1 modulates neuronal differentiation by its nuclear translocation. Proc Natl Acad Sci U S A 105(40):15599-604. https://doi.org/10.1073/pnas.0800612105

21. Jin Q, Yan T, Ge X, Sun C, Shi X, Zhai Q (2007) Cytoplasm-localized SIRT1 enhances apoptosis. J Cell Physiol 213(1):88-97. https: //doi.org/10.1002/jcp.21091

22. Johansen-Berg $\mathrm{H}$, Rushworth MF, Bogdanovic MD, Kischka U, Wimalaratna S, Matthews PM (2002) The role of ipsilateral premotor cortex in hand movement after stroke. Proc.Natl.Acad.Sci.U.S.A 99(22): 14518-14523. https://doi.org/10.1073/pnas.222536799

23. Kaeberlein M, McVey M, and Guarente L (1999) The SIR2/3/4 complex and SIR2 alone promote longevity in Saccharomyces cerevisiae by two different mechanisms. Genes Dev 13(19): 2570-2580.

24. Khoury N, Koronowski KB, Young JI, Perez-Pinzon MA (2018) The NAD(+)-dependent family of sirtuins in cerebral ischemia and preconditioning. Antioxid Redox Signal 28(8):691-710. https://doi.org/10.1089/ars.2017.7258

25. Krey L, Lühder F, Kusch K, Czech-Zechmeister B, Könnecke B, Fleming Outeiro T,Trendelenburg G (2015) Knockout of silent information regulator 2 (SIRT2) preserves neurological function after experimental stroke in mice. J Cereb Blood Flow Metab 35(12):2080-8. https://doi.org/10.1038/jcbfm.2015.178

26. Lee JK, Park MS, Kim YS, Moon KS, Joo SP, Kim TS, Kim JH, Kim SH (2007) Photochemically induced cerebral ischemia in a mouse model. Surg Neurol 67(6):620-5. https://doi.org/10.1016/j.surneu.2006.08.077

27. Li Y, Jiang N, Powers C, Chopp M (1998) Neuronal damage and plasticity identified by microtubule-associated protein 2, growth-associated protein 43, and cyclin D1 immunoreactivity after focal cerebral ischemia in rats. Stroke 29(9):1972-80. https://doi.org/10.1161/01.str.29.9.1972

28. Li Z, Pang L, Fang F, Zhang G, Zhang J, Xie M, Wang L (2012) Resveratrol attenuates brain damage in a rat model of focal cerebral ischemia via up-regulation of hippocampal Bcl-2. Brain Res 1450:116-24. https://doi.org/10.1016/j.brainres.2012.02.019 
29. Liu XA, Rizzo V, Puthanveettil SV (2012) Pathologies of axonal transport in neurodegenerative diseases. Transl Neurosci 3(4):355-372. https://doi.org/10.2478/s13380-012-0044-7

30. Luo J, Nikolaev AY, Imai S, Chen D, Su F, Shiloh A, Guarente L, Gu W (2001) Negative control of p53 by Sir2alpha promotes cell survival under stress. Cell 107(2):137-48. https://doi.org/10.1016/s0092-8674(01)00524-4

31. Magiera MM, Janke C (2014) Post-translational modifications of tubulin. Curr Biol 24(9):R351-4. https://doi.org/10.1016/j.cub.2014.03.032

32. Manders EM, Stap J, Brakenhoff GJ, vanDriel R, Aten JA (1992) Dynamics of threedimensional replication patterns during the S-phase, analyzed by double labeling of DNA and confocal microscopy. J Cell Sci 103(Pt 3):857-862.

33. Mao Z, Hine C, Tian X, Van Meter M, Au M, Vaidya A, Seluanov A, Gorbunova V (2011) SIRT6 promotes DNA repair under stress by activating PARP1. Science 332(6036):14431446. https://doi.org/10.1126/science.1202723

34. Maxwell MM, Tomkinson EM, Nobles J, Wizeman JW, Amore AM, Quinti L, Chopra V, Hersch SM, Kazantsev AG (2011) The Sirtuin 2 microtubule deacetylase is an abundant neuronal protein that accumulates in the aging CNS. Hum Mol Genet ;20(20):3986-96. https://doi.org/10.1093/hmg/ddr326

35. McCloy RA, Rogers S, Caldon CE, Lorca T, Castro A, Burgess A (2014) Partial inhibition of Cdk1 in G 2 phase overrides the SAC and decouples mitotic events. Cell Cycle 13:14001412. https://doi.org/10.4161/cc.28401

36. Michishita E, Park JY, Burneskis JM, Barrett JC, Horikawa I (2005) Evolutionarily conserved and nonconserved cellular localizations and functions of human SIRT proteins. Mol Biol Cell 16(10):4623-35. https://doi.org/10.1091/mbc.e05-01-0033

37. Miyake K, Yamamoto W, Tadokoro M, Takagi N, Sasakawa K, Nitta A, Furukawa S, Takeo S (2002) Alterations in hippocampal GAP-43, BDNF, and L1 following sustained cerebral ischemia. Brain Res 935(1-2):24-31. https://doi.org/10.1016/s0006-8993(02)02420-4

38. Nahhas F, Dryden SC, Abrams J, Tainsky MA (2007) Mutations in SIRT2 deacetylase which regulate enzymatic activity but not its interaction with HDAC6 and tubulin.Mol Cell Biochem 303(1-2):221-30. https://doi.org/10.1007/s11010-007-9478-6

39. Ng F, Wijaya L, Tang BL (2015) SIRT1 in the brain-connections with aging-associated disorders and lifespan. Front Cell Neurosci 9:64. https://doi.org/10.3389/fncel.2015.00064

40. Ng, F.; Tang, B.L (2015) Protein deacetylases and axonal regeneration. Neural Regen. Res 10(6): 870-1. https://doi.org/10.4103/1673-5374.158333 
41. Nie H, Hong Y, Lu X, Zhang J, Chen H, Li Y, Ma Y, Ying W (2014) SIRT2 mediates oxidative stress-induced apoptosis of differentiated PC12 cells. Neuroreport 25(11):838842. https://doi.org/10.1097/WNR.0000000000000192

42. North BJ, Marshall BL, Borra MT, Denu JM, Verdin E (2003) The human Sir2 ortholog, SIRT2, is an NAD+-dependent tubulin deacetylase. Mol Cell 11(2):437-44. https://doi.org/10.1016/s1097-2765(03)00038-8

43. Pfister JA, Ma C, Morrison BE, D'Mello SR (2008) Opposing effects of sirtuins on neuronal survival: SIRT1-mediated neuroprotection is independent of its deacetylase activity. PLoS One 3(12):e4090. https://doi.org/10.1371/journal.pone.0004090

44. Seitz RJ, Hoflich P, Binkofski F, Tellmann L, Herzog H, Freund HJ (1998) Role of the premotor cortex in recovery from middle cerebral artery infarction. Arch.Neurol 55(8): 1081-1088. https://doi.org/10.1001/archneur.55.8.1081

45. Shao W, Yang Y, Zhang Y, Lv C, Ren W, Chen C (2016) Involvement of BcStr2 in methionine biosynthesis, vegetative differentiation, multiple stress tolerance and virulence in Botrytis cinerea. Mol Plant Pathol 17(3):438-47. https://doi.org/10.1111/mpp.12292

46. She DT, Jo DG, Arumugam TV (2017) Emerging Roles of Sirtuins in Ischemic Stroke. Transl Stroke Res doi: 10.1007/s12975-017-0544-4. https://doi.org/10.1007/s12975-017$\underline{0544-4}$

47. Skoge RH, Ziegler M (2016) SIRT2 inactivation reveals a subset of hyperacetylated perinuclear microtubules inaccessible to HDAC6. J Cell Sci 129(15):2972-82. https://doi.org/10.1242/jcs. 187518

48. Stiess M, Bradke F (2011) Neuronal polarization: the cytoskeleton leads the way. Dev Neurobiol 71(6):430-44. https://doi.org/10.1002/dneu.20849

49. Stroemer RP, Kent TA, Hulsebosch CE (1993) Acute increase in expression of growth associated protein GAP-43 following cortical ischemia in rat. Neurosci Lett 162(1-2):51-4. https://doi.org/10.1016/0304-3940(93)90557-2

50. Sugino T, Maruyama M, Tanno M, Kuno A, Houkin K, Horio Y (2010) Protein deacetylase SIRT1 in the cytoplasm promotes nerve growth factor-induced neurite outgrowth in PC12 cells. FEBS Lett 584(13):2821-6. https://doi.org/10.1016/j.febslet.2010.04.063

51. Tang F, Guo S, Liao H, Yu P, Wang L, Song X, Chen J, Yang Q (2017) Resveratrol enhances neurite outgrowth and synaptogenesis via sonic hedgehog signaling following oxygen-glucose deprivation/reoxygenation injury. Cell Physiol Biochem 43(2):852-869. https://doi.org/10.1159/000481611 
52. Tanno M, Sakamoto J, Miura T, Shimamoto K, Horio Y (2007) Nucleocytoplasmic shuttling of the NAD+-dependent histone deacetylase SIRT1. J Biol. Chem 282(9):68236832. https://doi.org/10.1074/jbc.M609554200

53. Tennen RI, Chua KF (2011) Chromatin regulation and genome maintenance by mammalian SIRT6. Trends Biochem Sci 36(1):39-46. https://doi.org/10.1016/j.tibs.2010.07.009

54. Ueno Y, Chopp M, Zhang L, Buller B, Liu Z, Lehman NL, Liu XS, Zhang Y, Roberts C, Zhang ZG (2012) Axonal outgrowth and dendritic plasticity in the cortical peri-infarct area $\begin{array}{lllll}\text { after } & \text { experimental } & \text { stroke. } & \text { Stroke }\end{array}$ https://doi.org/10.1161/STROKEAHA.111.646224

55. Uzdensky A, Demyanenko S, Fedorenko G, Lapteva T, Fedorenko A (2017) Protein profile and morphological alterations in penumbra after focal photothrombotic infarction in the rat cerebral cortex. Mol Neurobiol 54(6):4172-4188. https://doi.org/10.1007/s12035-016-9964$\underline{5}$

56. Vaquero A, Scher MB, Lee DH, Sutton A, Cheng HL, Alt FW, Serrano L, Sternglanz R, Reinberg D (2006) SirT2 is a histone deacetylase with preference for histone H4 Lys 16 during mitosis. Genes Dev 20(10):1256-61. https://doi.org/10.1101/gad.1412706

57. Wang Z, Leng Y, Wang J, Liao HM, Bergman J, Leeds P, Kozikowski A, Chuang DM (2016) Tubastatin A, an HDAC6 inhibitor, alleviates stroke-induced brain infarction and functional deficits: potential roles of $\alpha$-tubulin acetylation and FGF-21 up-regulation. Sci Rep 6:19626. https://doi.org/10.1038/srep19626

58. Watson BD, Dietrich WD, Busto R, Wachtel MS, Ginsberg MD (1985) Induction of reproducible brain infarction by photochemically initiated thrombosis. Ann Neurol 17(5):497-504. https://doi.org/10.1002/ana.410170513

59. Wheeler TC, Chin LS, Li Y et al (2002) Regulation of synaptophysin degradation by mammalian homologues of seven in absentia. J Biol Chem 277(12):10273-2. https://doi.org/10.1074/jbc.M107857200

60. Xie XQ, Zhang P, Tian B, Chen XQ (2017) Downregulation of NAD-dependent deacetylase SIRT2 protects mouse brain against ischemic stroke. Mol Neurobiol 54(9):7251-7261. https://doi.org/10.1007/s12035-016-0173-z

61. Zhang W, Wei R, Zhang L, Tan Y, Qian C (2017) Sirtuin 6 protects the brain from cerebral ischemia/reperfusion injury through NRF2 activation. Neuroscience 366:95-104. https://doi.org/10.1016/j.neuroscience.2017.09.035

62. Zhang Y, Qiu B, Wang J, Yao Y, Wang C, Liu J (2017) Effects of BDNF-Transfected BMSCs on neural functional recovery and synaptophysin expression in rats with cerebral infarction. Mol Neurobiol 54(5):3813-3824. https://doi.org/10.1007/s12035-016-9946-7 
